\title{
Investigation of Pump Impeller Performance using CFD
}

\author{
V. Pandyaraj, S. Ravindran, R. Senthil Kumar and V. Aiswarya \\ Mechanical Engineering, Sri Sairam Engineering College, Chennai - 600044, Tamil Nadu, India; pandyaraj.raj1@ \\ gmail.com, ravindran.research@gmail.com, senthilkumar.mech@sairam.edu.in, aiswaryavsri@gmail.com
}

\begin{abstract}
Objectives: Impeller is the rotating component of a centrifugal pump which imparts kinetic energy on the working fluid. The present work is concentrated on the optimization of geometry of the impeller to increase the efficiency of centrifugal pump. Methods/Statistical Analysis: The L9 orthogonal array table is formed by taking the parameters such as impeller width, number of blades and inlet diameter and outlet blade angle as control factors and efficiency as response. The impeller is modelled using the software Pro_E and the analysed using CFD software Fluent 6.3 by assuming the steady, incompressible and viscous flow condition for the working fluid. Findings: The optimization technique is carried out based on taguchi concept with the aid of CFD software. From the contribution ratio values it is found that the parameter Number of Blades contributes a significant portion in affecting the pump efficiency. Based on the values of pressure, discharge and torque obtained from the software, the corresponding values of efficiencies are calculated. Application/Improvement: Using larger the better quality characteristics, the geometry of the impeller is optimized for maximum efficiency.
\end{abstract}

Keywords: CFD and Optimization, Efficiency, Impeller, Vane

\section{Introduction}

Over the last few decades, lots of works are focused on the impeller area in order to improve the performance of the pump. Water pump impellers displayed more complexity and this complexity can be studied with the aid of CFD software, hence improving the pump design. This method is used for the detailed study of the behavior of flow and the regions of separation with a high accuracy. For a given flow rate, the inlet conditions depend on the height difference between the inlet plane and the lower reservoir.

A compressible time marching method was used by $\mathrm{Oh}$ and Rho and CFX-TASC flow to virtualize the pattern of flow in a pump and compared these methods in obtaining the pump's performance. The results of these methods were set side by side in order to improve the performance of the pump. As with the flow in a pipe or over a flat plate, energy losses in turbo machinery depend on Reynolds number Re and relative surface roughness $\varepsilon / d$.
The 3D Navier-stokes codef by Dawes for a mixed flow pump were assured when Goto compared the actual and analyzed exit flow-fields of impeller and several clearances inclosing the impellers. A pseudo compressibility technique was employed by Zhou and $\mathrm{Ng}$ to develop a 3D Navier-stokes solver for the flow study through a mixed flow centrifugal type impeller the findings were compared with the published measured and analyzed results and then finalized.

The fluid dynamics software's like CFX-TASC flow, FLUENT, STARCD were used by Kaupert, Potss and Sun and Tsukamoto to study the off-design performance of the pump. Though, they found the reverse flow with numerically small flow rates in the shrouded region of the impeller, some contradictions continued to exist. Kaupert's CFD results did not succeed to extract the arithmetic values of the outlet reverse flow, although his experiments revealed the existence of reverse flow in the shrouded region of impeller inlet and outlet. By unveiling the experimental data over a range, Sun and Tsukamoto endorsed the anticipated results of the radial forces acting

\footnotetext{
*Author for correspondence
} 
in the impeller, the head-flow and the inlet pressure distribution of the diffuser They obtained the reverse flow at minimal rates, but they did not stimulate the precise pattern of back- flow along the outlet. They proved the need for the off-design performance in pumps. The volute and the impeller of a centrifugal pump had been 3D-CFD simulated by using CFX codes. . Long discussions by site personnel were required to work through issues involving processes that are dovetailed together to form our understanding of the requirements]. The outside impeller diameter of $400 \mathrm{~mm}$ and specific speed of 32 (metric units) of the pump gives its specification. After the flow in the impeller with a structured grid is $3 \mathrm{D}$ simulated, the quality of grid and the turbulence were analyzed. A simulation of three dimensional quasi unsteady flows for the impeller-volute stage was carried on in the obtained impeller model. The procedure for the design of the volute and interface passage between volute and impeller were discussed. The simulation of flow was performed for blades and tongue of the volute at several analogous positions. Velocity and pressure field were determined for various flow rates, permitting them to access the radial forces acting on the shaft of the pump. The energy transfer quantities are losses between fluid power and mechanical power of the impeller or runner?. The different methods developed by highly experienced and accomplished hydraulic engineers like Lebonoff, Kurowzski, Anderson and Lazarkiewicz also have elements of empirical design. Shojaeefard, Tahani, Ehghaghi, Fallahian and Beglari carried out experimental study for performance improvement of centrifugal pump by modifying the geometric characteristics using CFD for viscous fluid if

\section{Specification of the Existing Model}

Width of the impeller $13 \mathrm{~mm}$, number of blades 8 , inlet diameter of the impeller $51 \mathrm{~mm}$, cheaply on account of the smaller conversion of kinetic energy in to pressure energy in the casing Outlet Blade angle is $28^{\circ}$. Speed $(\mathrm{N})=2800$ rpm, Specific speed 127.43, Discharge (Q) 0.0048116115 $\mathrm{m}^{3} / \mathrm{s}$, Pressure (p) $1,12,808.78$ Pascal, Angular velocity $(2 \pi \mathrm{N}) / 60=(2 \pi \times 2800) / 60=293.2 \mathrm{rad} / \mathrm{s}$, Velocity $14 \mathrm{~m} / \mathrm{s}$, Head 10 m, Hydraulic efficiency $\left(\mathrm{n}_{\mathrm{h}}\right) 78.12 \%$, Volumetric efficiency $\left(n_{v}\right) 94 \%$, Overall efficiency $\left(n_{o}\right) 74 \%$. The boundary conditions are taken in such a way that the outlet pressure as 1 bar and the wall roughness constant as 0.5 . The fluid is of steady, incompressible and viscous fluid. Density of water is $998.2 \mathrm{~kg} / \mathrm{m}^{3}$. Specific heat of water $4182 \mathrm{~J} / \mathrm{Kg}-\mathrm{K}$. Thermal conductivity of water 0.6 $\mathrm{w} / \mathrm{m}-\mathrm{k}$, density of Aluminum $2719 \mathrm{~kg} / \mathrm{m}^{3}$, Specific heat of aluminum $871 \mathrm{~J} / \mathrm{kg}-\mathrm{k}$, Thermal conductivity of aluminum is $202.4 \mathrm{w} / \mathrm{m}-\mathrm{k}$ (Figure 1 ).

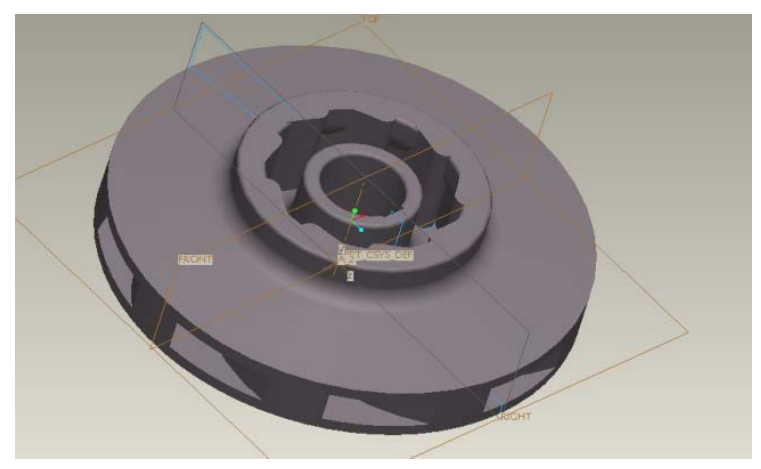

Figure 1. Model of the existing impeller.

\section{Control Factors and Levels}

Control factors' values are decided by the designer. Levels are values allotted to the factor. Parameters considered in this study are impeller width, Number of Blades, Inlet diameter of impeller and the outlet Blade angle of the impeller (Table 1).

Table 1. Control factors and levels

\begin{tabular}{|l|c|c|c|}
\hline \multirow{2}{*}{ Control factors } & \multicolumn{3}{|c|}{ Factor levels } \\
\cline { 2 - 4 } & Level 1 & Level 2 & Level 3 \\
\hline Impeller width (mm) & 10 & 12 & 14 \\
\hline Number of Blades & 4 & 6 & 7 \\
\hline $\begin{array}{l}\text { Inlet Diameter of the impeller } \\
\text { (mm) }\end{array}$ & 46 & 50 & 56 \\
\hline Outlet Blade angle (degree) & 24 & 26 & 30 \\
\hline Control factors & \multicolumn{3}{|c|}{ Factor levels } \\
\cline { 2 - 4 } & Level 1 & Level 2 & Level 3 \\
\hline Impeller width (mm) & 10 & 12 & 14 \\
\hline Number of Blades & 4 & 6 & 7 \\
\hline $\begin{array}{l}\text { Inlet Diameter of the impeller } \\
\text { (mm) }\end{array}$ & 46 & 50 & 56 \\
\hline Outlet Blade angle (degree) & 24 & 26 & 30 \\
\hline
\end{tabular}

Experiments have been conducted with $\mathrm{L}_{9}\left(3^{4}\right)$ orthogonal array $\mathrm{L}_{9}$ orthogonal array has been considered since it provides a lot of information with minimum number of experiments and less time 
consuming for conducting experiments. Orthogonal array permits researchers to understand several parameters of design and to predict the effect of them independently (Table 2).

Table 2. Assigned values to an orthogonal array

\begin{tabular}{lcccc}
\hline $\begin{array}{l}\text { Exp. } \\
\text { No }\end{array}$ & $\begin{array}{c}\text { Impeller } \\
\text { width } \\
(\mathbf{m m})\end{array}$ & $\begin{array}{c}\text { Number } \\
\text { of Blades }\end{array}$ & $\begin{array}{c}\text { Inlet Diameter } \\
\text { of the impeller } \\
(\mathbf{m m})\end{array}$ & $\begin{array}{c}\text { Outlet } \\
\text { Blade angle } \\
\text { (degree) }\end{array}$ \\
\hline 1 & 10 & 4 & 46 & 24 \\
2 & 10 & 6 & 50 & 26 \\
3 & 10 & 7 & 56 & 30 \\
4 & 12 & 4 & 50 & 30 \\
5 & 12 & 6 & 56 & 24 \\
6 & 12 & 7 & 46 & 26 \\
7 & 14 & 4 & 56 & 26 \\
8 & 14 & 6 & 46 & 30 \\
9 & 14 & 7 & 50 & 24 \\
\hline
\end{tabular}

\section{Work Methodology}

The impeller has been modeled using Pro_E software. The flow analysis has been studied using CFD software FLUENT 6.3. CFD is used for simulating the conduct of a system that includes flow pattern of fluid, exchange of heat and other process. It solves the equations of flow over an area with boundary conditions over the particular domain. The technique of meshing is followed for creating a sliding mesh as the analysis is unsteady. Once the pump geometry has been specified and a mesh has been created automatically, where the flow equations need to be solved I $^{2}$. CFD plays an important role in almost every branch of fluid dynamics, from aerospace industry to weather forecast. The CFD can be related to the broad topic containing numerical solution, the governing equations of the fluid flow, the set of Navier-stokes equations, any additional conservation equations The main stages in CFD study are pre-processor, solver and post-processor. The pre-processor is a component used to create the input for the solver. The solver is a component, which solves CFD problem, producing the desired results. The post-processor is a component used to analyze and present the results.

Pre-processing: Formulate problem, Governing equations and boundary conditions; construct mesh.

Solving: Numerical solution of the given equation.

Post-processing: plot and analyze the results.

\section{Software Simulation}

Impeller model, meshed model and cut section of the volume mesh for an impeller is shown in Figure 2. Pressure distribution for impeller is displayed in Figure 3. Velocity distribution for impeller 2 is shown in Figure 4. Results obtained using CFD software (Table 3). The values of efficiency are calculated by using the data obtained from the software results. Efficiencies obtained from CFD values (Table 4). Calculated SN value ratios are tabulated (Table 5).

Main Effects Plot for SN Ratio is given (Figure 5). Response curves are drawn (Figure 6). Optimum values for impeller are shown (Table 6).

The Anova table for efficiency is calculated and the optimum value of the impeller is calculated and the contribution ratio for each parameter is obtained. The confidential interval is predicted

$\mu$ predicted- $\mathrm{CI} \leq \mu$ predicted $\leq \mu$ predicted $+\mathrm{CI}$

$80.86-1.674 \leq 80.86 \leq 80.86+1.674$

$79.186 \leq 80.86 \leq 82.534$ calculated response values are tabulated (Table 7). Percentage contributions of parameters are plotted (Figure 7). SN ratio comparisons are made (Figure 8).

From the PARETO ANOVA table the contribution ratio of each factor had been calculated. It is clear that the number of blades affects the efficiency more when compared to other factors and in this case the outlet blade angle contribution is very less. The significant factors are chosen from the left-hand side in the Pareto diagram which cumulatively contributes about $90 \%$. From the chart it is found that the factors number of blades, inlet diameter and the impeller width are identified as significant variables for the centrifugal pump impeller, since its cumulative contribution ratio comes to $90 \%$. Here we can that if the number of blades decreases from the optimum designed value there is a chance for the turbulence to occur, as well as if the blade exceeds then there is a chance for the restriction in the flow path which paves the way for reverse flow to occur which significantly affects the efficiency of the pump. With the increase of blade number, the head of centrifugal pump grows all the time ${ }^{\text {A }}$. It is also found that if the inlet diameter of the pump is very high then there will be more discharge but the head will be less. The impeller width plays third in this case; here the optimal value obtained is $10 \mathrm{~mm}$ which is less than the other levels $(12 \mathrm{~mm}, 14 \mathrm{~mm})$. The outlet 
angle plays the last role in our case. From study it reveals that the outlet angle plays ore vital role in case of more viscous fluid medium than water (Agricultural Pump). Pressure distributions for Optimum value are plotted (Figure 9). Velocity distributions for Optimum valueis shown Figure 10.
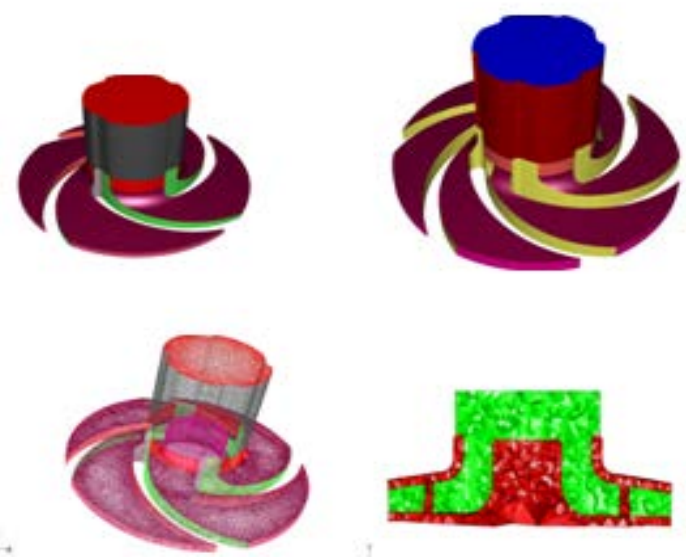

Figure 2. Impeller model, Meshed model and cut section of the volume mesh for an impeller.
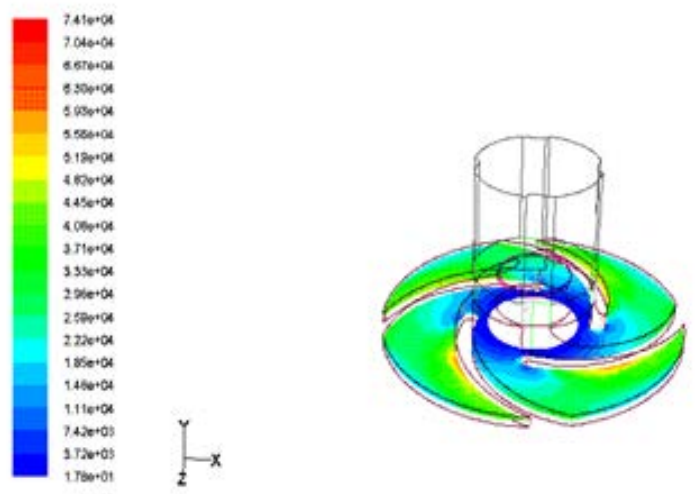

Figure 3. Pressure distribution for impeller 1.
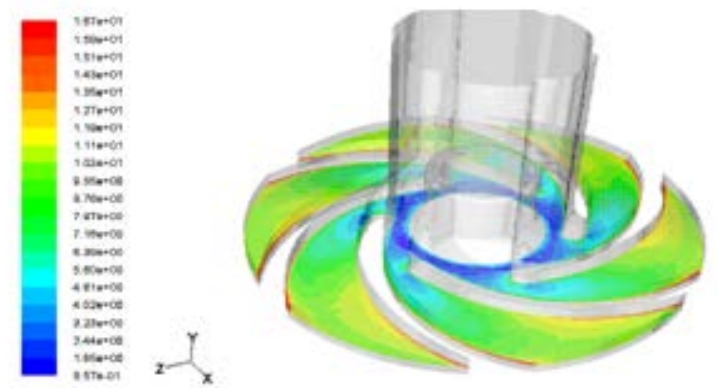

Figure 4. Velocity distribution for impeller 2.

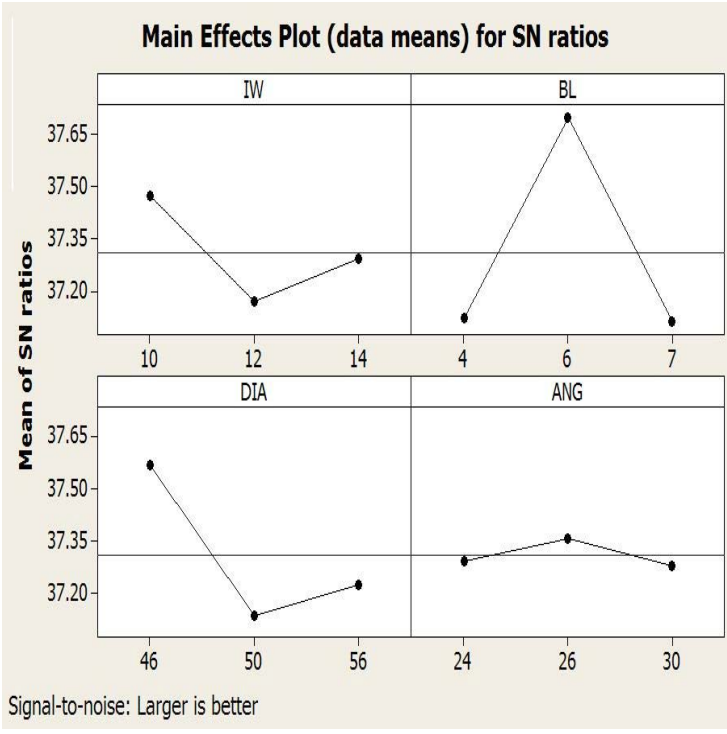

Figure 5. Main effects plot for SN ratio.

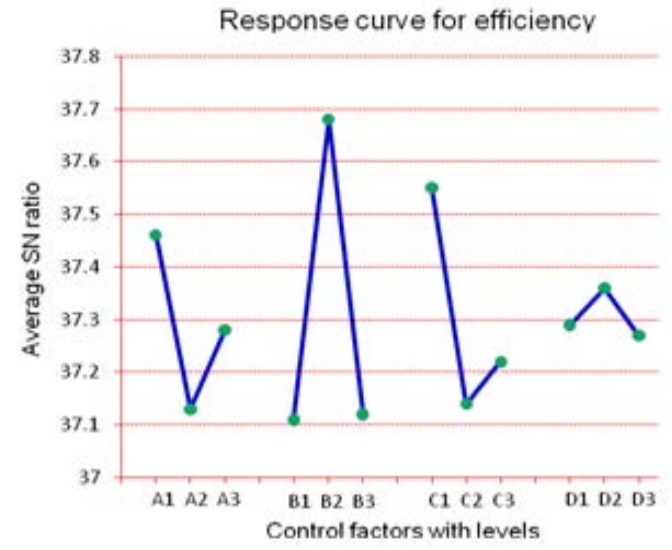

Figure 6. Response curves.

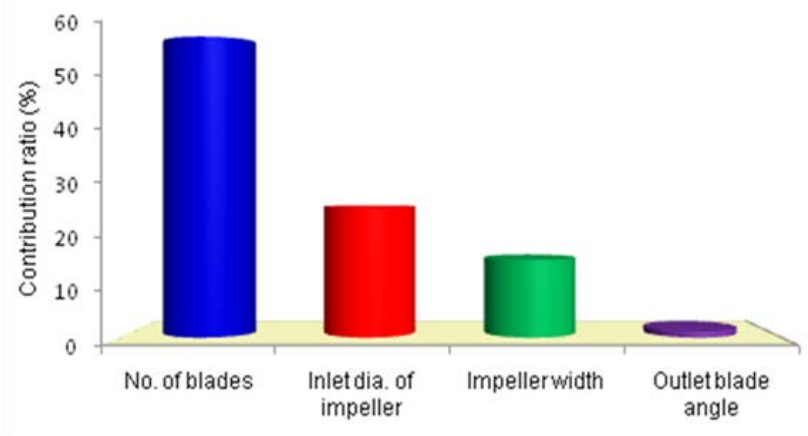

Figure 7. Percentage contributions of parameters. 


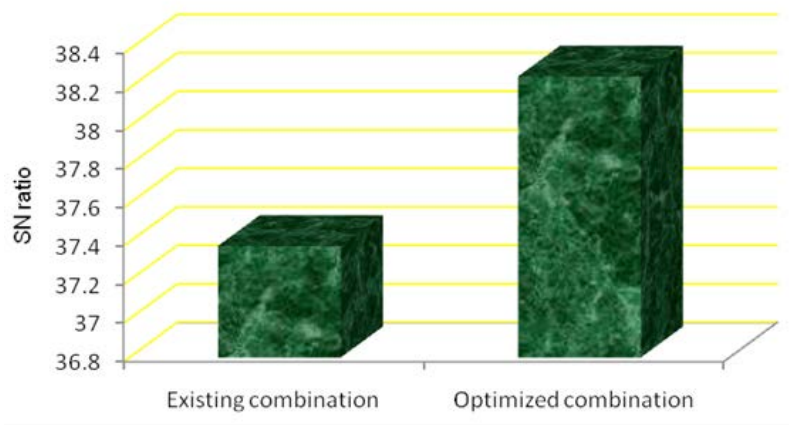

Figure 8. SN ratio comparisons.
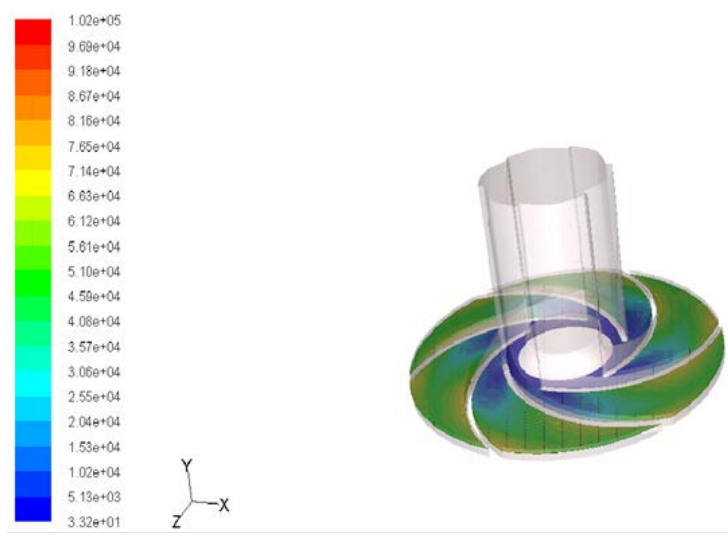

Figure 9. Pressure distributions for optimum value.
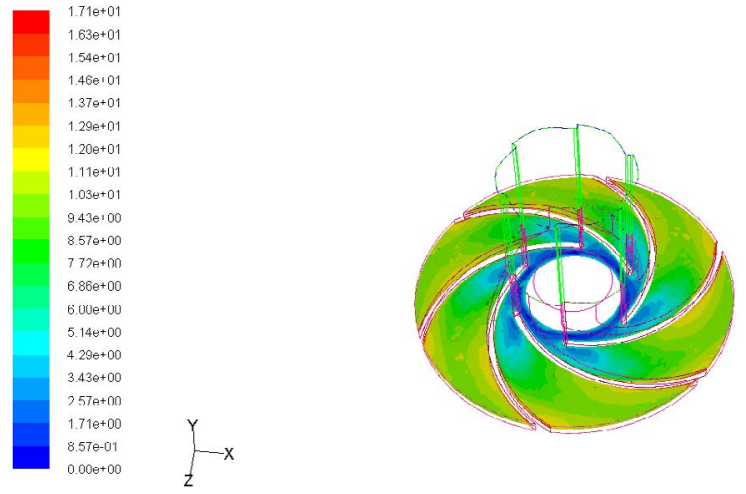

Figure 10. Velocity distributions for optimum value.

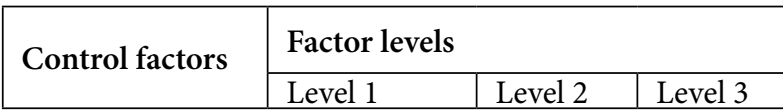

Table 3. Results obtained using CFD software

\begin{tabular}{lccc}
\hline Exp No & Velocity $(\mathrm{m} / \mathrm{s})$ & Head(m) & Specific speed \\
\hline 1 & 15.86 & 13.0 & 88.66 \\
2 & 16.00 & 14.0 & 77.00 \\
3 & 13.01 & 9.0 & 102.1 \\
4 & 11.70 & 7.0 & 123.6 \\
5 & 14.30 & 10.42 & 113.0 \\
6 & 13.70 & 9.5 & 131.80 \\
7 & 13.10 & 8.8 & 100.85 \\
8 & 16.80 & 14.4 & 97.07 \\
9 & 13.04 & 8.5 & 135.09 \\
Optimal Value & 16.9 & 14.6 & 94.70 \\
\hline
\end{tabular}

Table 4. Efficiencies obtained from CFD values

\begin{tabular}{lccc}
\hline S.no & $\begin{array}{c}\text { Volumetric } \\
\text { Efficiency(\%) }\end{array}$ & $\begin{array}{c}\text { Hydraulic } \\
\text { Efficiency(\%) }\end{array}$ & $\begin{array}{c}\text { Overall } \\
\text { Efficiency(\%) }\end{array}$ \\
\hline 1 & 96.00 & 78.12 & 75.00 \\
2 & 95.00 & 81.10 & 77.045 \\
3 & 93.00 & 74.00 & 72.00 \\
4 & 96.70 & 71.32 & 69.00 \\
5 & 94.32 & 79.27 & 74.60 \\
6 & 93.20 & 77.52 & 73.12 \\
7 & 93.60 & 76.10 & 71.32 \\
8 & 95.30 & 82.10 & 78.24 \\
9 & 92.30 & 75.61 & 70.12 \\
Optimum & 97.60 & 82.86 & 80.87 \\
\hline
\end{tabular}

Table 5. Calculated SN ratio values

\begin{tabular}{lccc}
\hline S. No & mean & S/Nratio & Std deviation \\
\hline 1 & 75.20 & 37.5243 & 0.2000 \\
2 & 77.050 & 37.7354 & 0.1000 \\
3 & 72.067 & 37.1570 & 0.2802 \\
4 & 69.00 & 36.7769 & 0.1600 \\
5 & 74.61 & 37.4559 & 0.1153 \\
6 & 73.08 & 37.2760 & 0.0721 \\
7 & 71.32 & 37.0642 & 0.1200 \\
8 & 78.56 & 37.9038 & 0.6373 \\
9 & 70.01 & 36.9032 & 0.0265 \\
\hline
\end{tabular}


Table 6. Optimum values for impeller

\begin{tabular}{|c|c|c|c|c|}
\hline S.no & $\begin{array}{l}\text { Impeller } \\
\text { width } \\
(\mathrm{mm}) \\
\end{array}$ & $\begin{array}{l}\text { No. of } \\
\text { Blades In }\end{array}$ & $\begin{array}{c}\text { Inlet dia of } \\
\text { Impeller }(\mathrm{mm})\end{array}$ & $\begin{array}{c}\text { Outlet } \\
\text { Blade } \\
\text { angle }\left(^{\circ}\right) \\
\end{array}$ \\
\hline $\begin{array}{l}\text { Optimum } \\
\text { Value } \\
\end{array}$ & 10 & 6 & 46 & 26 \\
\hline \multicolumn{5}{|c|}{ Calculated response value } \\
\hline SOURCE & $\begin{array}{c}\text { IMPELLE-R } \\
\text { WIDTH }\end{array}$ & $\begin{array}{c}\text { No. OF } \\
\text { BLADES }\end{array}$ & $\begin{array}{c}\text { INLET } \\
\text { SIA. OF } \\
\text { IMPELLE-R } \\
\end{array}$ & $\begin{array}{c}\text { OUTLET } \\
\text { BLADE } \\
\text { ANGLE }\end{array}$ \\
\hline Level 1 & 74.722 & 71.84 & 75.61 & 73.27 \\
\hline Level 2 & 72.23 & 76.41 & 72.02 & 73.81 \\
\hline Level 3 & 73.297 & 71.719 & 72.66 & 73.21 \\
\hline $\begin{array}{l}\text { Differ- } \\
\text { ence }\end{array}$ & 2.542 & 5.021 & 3.59 & 0.60 \\
\hline RANK & 3 & 1 & 2 & 4 \\
\hline
\end{tabular}

\section{Conclusion}

The impact of impeller width, number of blades and the impeller inlet diameter and blade angle at outlet on a centrifugal pump impeller had been inspected deeply in this project. In this project, by the optimization of the geometry of the impeller, the performance of the pump had been improved from $74 \%$ to $80.87 \%$. Here the control factors such as impeller width, number of blades, and inlet diameter of the impeller were taken and the outlet blade angle and efficiency was taken as response. The optimization technique is carried out based on taguchi concept with the aid of CFD software. From the contribution ratio values it is found that the parameter number of blades plays a significant role in affecting the efficiency of the pump. The inlet diameter of the impeller ranks second whereas the impeller width stands third. And in this case the contribution of the outlet angle is very less when compared to the other control factors.

\section{References}

1. Athavale MM, Li HY, Jiang Y, Singhal AK. Application of the full cavitation model to pumps and inducers. USA In- ternational Journal of Rotating Machinery. 2002; 8(1):4556.

2. Weidong Zhou, Zhimei Zhao, T. S. Lee, and S. H. Winoto. A NUMERICAL SIMULATION OF THE IMPELLER-VOLUTE INTERACTION IN

3. A CENTRIFUGAL PUMP

4. Mentsoz MD, Filios AE, Margaris DP, Papanikas DG. A numerical simulation of the impeller-volute interaction in a centrifugal pump. 1st International Conference from Scientific Computing to Computational Engineering, 1st ICSCCE; Athens. 2004 Sept.

5. Gulich JF, Pumps S. Effect of Reynolds-number and surface roughness on the efficiency of centrifugal pumps. American Society of Mechanical Engineering Journal of Fluids Engineering. 2003; 125(4):670-9.

6. Storteig E. Dynamic characteristics and leakage performance of liquid annular seals in centrifugal pumps. NTNU Submitted; 1999. p. 1-200.

7. Zhou W, Zhao Z, Lee TS, Winoto SH. Investigation of flow through centrifugal pump impellers using computational fluid dynamics. International Journal of Rotating Machinery. 2003; 9(1):49-61.

8. Shukla SN, Kshirsagar JT. Numerical experiments on a centrifugal pump. American Society of Mechanical Engineering. 2003. p. 21-30.

9. Scarbrough TG. Pumps and in service testing. Proceedings of the Ninth NRC/ASME Symposium on Valves; L'Enfant Plaza Hotel Washington, DC. 2006 Jul. p. 1-14.

10. Oh HW, Chung MK. Optimum values of design variables versus specific speed for centrifugal pumps. Proceedings of the Institution of Mechanical Engineers.. 1999; 213(3):219.

11. Thin KC, Khaing MM, Aye KM. Design and performance analysis of centrifugal pump. World Academy of Science, Engineering and Technology; 2008. p. 422-9.

12. Singh RR, Nataraj M. Design and analysis of pump impeller using SWFS. World Journal of Modelling and Simulation. 2014; 10(2):152-60.

13. Church AH, Lal J. Centrifugal pumps and blowers. US: Krieger Publishing Company; 1972.

14. Nigussie T, Dribssa E. Design and CFD analysis of centrifugal pump. International Journal of Engineering Research and General Science. 2015 May-Jun; 3(3):668-77.

15. Addison H. Centrifugal and other rotadynamic pumps. $3 \mathrm{rd}$ ed. London: Chapman \& Hall Ltd: 1966. p. 565.

16. Liu H, Wang Y, Yuan S, Tan M, Wang K. Effects of blade number on characteristics of centrifugal pumps. Chinese Journal of Mechanical Engineering. 2010. DOI: 10.3901/ CJME. 